\title{
Carmustine/Dacarbazine/Hydroxyurea Regimen
}

National Cancer Institute

\section{Source}

National Cancer Institute. Carmustine/Dacarbazine/Hydroxyurea Regimen. NCI

Thesaurus. Code C9951.

A chemotherapy regimen consisting of dacarbazine, hydroxyurea, and carmustine for the treatment of melanoma. 